\title{
Ion exchange and binding in selenium remediation materials using DNP-enhanced solid-state NMR spectroscopy
}

\author{
Marco Mais ${ }^{\dagger}$ Javier Torroba $\ddagger^{\ddagger}$ Nathan S. Barrow ${ }^{\ddagger}$, Subhradip Paul\$ and Jeremy J. Titman ${ }^{\dagger}$ \\ tSchool of Chemistry, University of Nottingham, University Park, Nottingham, NG7 2RD, UK \\ ¥Johnson Matthey Technology Centre, Blounts Court, Sonning Common, Reading, RG4 9NH, UK \\ §Nottingham DNP MAS NMR Facility, Sir Peter Mansfield Imaging Centre, University Park, Nottingham, NG7 \\ $2 R D, U K$
}

*Corresponding author: Email: Jeremy.Titman@nottingham.ac.uk, Tel: +44 1159513560

\begin{abstract}
Selenate-loaded selenium water remediation materials based on polymer fibres have been investigated by dynamic nuclear polarization (DNP) enhanced solid-state NMR. For carbon-13 a significant reduction in experiment time is obtained with DNP even when compared with conventional carbon-13 NMR spectra recorded using larger samples. For the selenium remediation materials studied here this reduction allows efficient acquisition of $\left\{{ }^{1} \mathrm{H}\right\}{ }^{-77} \mathrm{Se}$ heteronuclear correlation spectra which give information about the nature of the binding of the remediated selenate ions with the grafted side chains which provide the required ion exchange functionality.
\end{abstract}

\section{Introduction}

Solid-state nuclear magnetic resonance (NMR) is a powerful method for studying the molecular structure and dynamics of a broad range of advanced materials. Solid-state NMR suffers from low sensitivity, because of the small nuclear spin polarizations involved even with high magnetic fields, and so long acquisition times or large sample volumes are often required. The problem of sensitivity becomes overwhelming for dilute species, so that measurements of surface sites, molecules at interfaces or isotopes with low natural abundance are often impossible. Fortunately, weak NMR signals can be enhanced by dynamic nuclear polarization (DNP), ${ }^{1-5}$ which involves transfer of electron spin polarization from radicals ${ }^{6-9}$ implanted in the sample to nearby nuclei. This process requires the saturation of the electronic Zeeman transitions and is most efficient at low temperatures ( $<100 \mathrm{~K})$. Until recently DNP has been limited to low magnetic fields because of the lack of high-frequency, 
high-power microwave sources. However, developments in the design of gyrotrons ${ }^{10}$ have made DNP spectrometers operating at ${ }^{1} \mathrm{H}$ NMR frequencies up to $900 \mathrm{MHz}$ possible. The substantial enhancements $(>100-$ fold) obtained with DNP make NMR studies of dilute species feasible for the first time and have prompted many new NMR applications to catalysts, surfaces and interfaces, ${ }^{11-18}$ porous materials ${ }^{19-23}$ and nano- and microscale particles. ${ }^{24-26}$

Selenium is a minor component of the earth's crust, occurring with an abundance of $\sim 0.05 \mathrm{ppm}$ and often appearing in association with sulfur-containing minerals. ${ }^{27}$ The most significant anthropogenic sources of Se contamination in the environment include coal burning, the smelting of sulfide ores and glass manufacture. Although elemental Se is an essential trace nutrient which is incorporated into several animal enzymes, many water-soluble Se compounds are highly toxic, with a median lethal dose between 1.5 and $6 \mathrm{mg} / \mathrm{kg}$ body weight in many animal species. ${ }^{28} \mathrm{~A}$ maximum concentration of $40 \mu \mathrm{g} \mathrm{dm}{ }^{-3}$ is recommended for drinking water by the World Health Organization, ${ }^{29}$ although many organizations, including the EU, ${ }^{30}$ decree a lower guideline value of $10 \mu \mathrm{g} \mathrm{dm}^{-1}$. In alkaline soils, Se is present as water-soluble selenate $\left(\mathrm{SeO}_{4}{ }^{2-}\right)$ which is easily leached into rivers, and the concentration of Se in groundwater and surface water in some areas can approach as much as $0.4 \mathrm{mg} \mathrm{dm}^{-3} \cdot{ }^{28}$ Reproductive failure in fish occurs at waterborne Se concentrations of just a few $\mu \mathrm{g}$ $\mathrm{dm}^{-3}$, so aquatic Se contamination can have widespread consequences beyond drinking water issues.

Efficient Se remediation requires low concentrations of a wide range of Se species to be removed from large volumes of water, often in the presence of significantly higher concentrations of sulfur. For example, waste water from oil refineries typically contains a few $\mathrm{mg} \mathrm{dm}^{-3} \mathrm{SeO}_{4}{ }^{2-}$ and selenocyanate $(\mathrm{SeCN}-)$, but more than 10 times that amount of sulfate $\left(\mathrm{SO}_{4}^{2-}\right)$. Hence, many conventional treatment processes, based on natural and synthetic absorbents and coagulants are ineffective for removing $\mathrm{SeO}_{4}{ }^{2-}$ from water, often because they lack the necessary capacity or selectivity. Current technologies include chemical methods based on reduction by nanoscale zero-valent iron, bioremediation by specific bacterial strains in anaerobic tank or packed bed reactors, physical approaches, including reverse osmosis and nanofiltration, as well as polymer fibres and resins with strong-base ion-exchange functionality. ${ }^{31-34}$

The Se remediation material investigated here is based on Johnson Matthey's Smopex ${ }^{\circledR}-103$ synthetic scavenger, ${ }^{35}$ consisting of trilobal polypropylene fibres cut to a length of $300 \mu \mathrm{m}$ during manufacturing. This contrasts with standard spherical porous resin beads used in common adsorption or ion exchange processes where the functionality is not fully exposed to solution, and this results in high capacity loading of $\mathrm{SeO}_{4}{ }^{2-}$ and 
SeCN- ions. Strong-base functionality, which gives the advantage of a broad $\mathrm{pH}$ range, is provided via grafted 1-(phenyl)- $N, N, N$-trimethylmethanaminium cation sidechains with chloride exchangeable anions. These materials have been shown to give very fast rates of ion exchange and good selectivity in competitive $\mathrm{SCN}^{-}$ $/ \mathrm{SO}_{4}{ }^{2-}$ feeds compared to standard resin bead ion exchangers. ${ }^{35} \mathrm{In}$ this paper we describe a DNP-enhanced solid-state NMR study of these Se remediation materials aimed at identifying the location and the nature of the binding of the $\mathrm{SeO}_{4}{ }^{2-}$ anion after ion exchange.

\section{Experimental}

\section{Selenate-loaded Materials}

A $5.5 \mathrm{wt} \%$ selenate-loaded Smopex®-103 sample was prepared by ion exchange with an aqueous solution of $\mathrm{NaSeO}_{4} .250 \mathrm{~mL}$ of an aqueous solution of sodium selenate were added to $3.4 \mathrm{~g}$ (wet weight) of Smopex®-103. The ion-exchange process took place overnight on a roller-mixer at room temperature. The resulting solid was filtered, washed with demineralized water $(3 \times 50 \mathrm{~mL})$, air dried and left overnight in a vacuum oven at $40^{\circ} \mathrm{C}$.

\section{Conventional solid-state NMR Experiments}

$\left\{{ }^{1} \mathrm{H}\right\}{ }^{13} \mathrm{C} C P M A S$ NMR experiments were performed on a Bruker Avance III, equipped with a $4 \mathrm{~mm} \mathrm{HCN}$ triple-resonance MAS probe, operating at a ${ }^{13} \mathrm{C}$ Larmor frequency of $150.9 \mathrm{MHz}$. Zirconia rotors were used, with MAS rates regulated to $\pm 1 \mathrm{~Hz} .{ }^{13} \mathrm{C}$ chemical shifts were referenced to TMS using the high frequency resonance of adamantane (38.5 ppm) as an external secondary reference. Further experimental details are given in the text and the figure captions.

\section{DNP-enhanced solid-state NMR Experiments}

For DNP, $32 \mathrm{mg}$ of selenate-loaded Smopex ${ }^{\circledR}-103$ was wetness impregnated with a $16 \mathrm{mM}$ solution of the biradical AMUPol in $20 \mu \mathrm{L}$ of glycerol- $\mathrm{d}_{8} / \mathrm{D}_{2} \mathrm{O} / \mathrm{H}_{2} \mathrm{O} 60: 30: 10 \mathrm{v} / \mathrm{v} / \mathrm{v}$. The wet solid was packed into a $3.2 \mathrm{~mm}$ sapphire rotor sealed with a Teflon plug and a zirconia cap. DNP-enhanced ${ }^{13} \mathrm{C}$ and ${ }^{77} \mathrm{Se}$ solid-state NMR experiments were performed on a Bruker Avance III HD $600 \mathrm{MHz}$ spectrometer, equipped with a $3.2 \mathrm{~mm}$ lowtemperature triple-resonance MAS probe, operating at ${ }^{13} \mathrm{C}$ and ${ }^{77} \mathrm{Se}$ Larmor frequencies of $150.9 \mathrm{MHz}$ and 114.6 $\mathrm{MHz}$, respectively. DNP was achieved by irradiating the sample with high-power microwaves (10 W at the centre of the waveguide) at a frequency of $395 \mathrm{GHz}$, generated by a gyrotron that operated continuously (stability of better than $\pm 1 \%$ ). Thick-walled sapphire rotors were used for all DNP experiments, with MAS 
rates regulated to $\pm 10 \mathrm{~Hz}$. The sample temperature was $93 \pm 3 \mathrm{~K}$ with the microwaves off and $100 \pm 3 \mathrm{~K}$ with the microwaves on. Further experimental details are given in the text and the figure captions.

\section{Results and Discussion}

\section{Conventional Solid-state ${ }^{13}$ C NMR}

Figure 1 shows the conventional $\left\{{ }^{1} \mathrm{H}\right\}-{ }^{13} \mathrm{C}$ CPMAS spectra of $(\mathrm{A})$ unloaded and (B) $5.5 \mathrm{wt} \%$ selenate-loaded Smopex ${ }^{\circledR}-103$ recorded using a $4 \mathrm{~mm}$ triple resonance MAS probe at a Larmor frequency of $150.9 \mathrm{MHz}$ and a MAS rate of $12 \mathrm{kHz}$. The two spectra are essentially identical, suggesting that this concentration of loaded selenate anion does not cause an observable change to the ${ }^{13} \mathrm{C}$ NMR spectrum of the polymer or the functionalizing sidechains. In both spectra the ${ }^{13} \mathrm{C}$ resonances from the polypropylene fibres are present at approximately 21, 26 and $44 \mathrm{ppm}$, while the $N$-methyl groups and the methanaminium carbon from the functionalizing $N, N, N$-trimethylmethanaminium cations appear at 53 and $69 \mathrm{ppm}$, respectively. Note that the spectrum of selenate-loaded Smopex ${ }^{\circledR}-103$ required 512 scans and, with a relaxation delay of $2.50 \mathrm{~s}$, took approximately 10 mins to record.

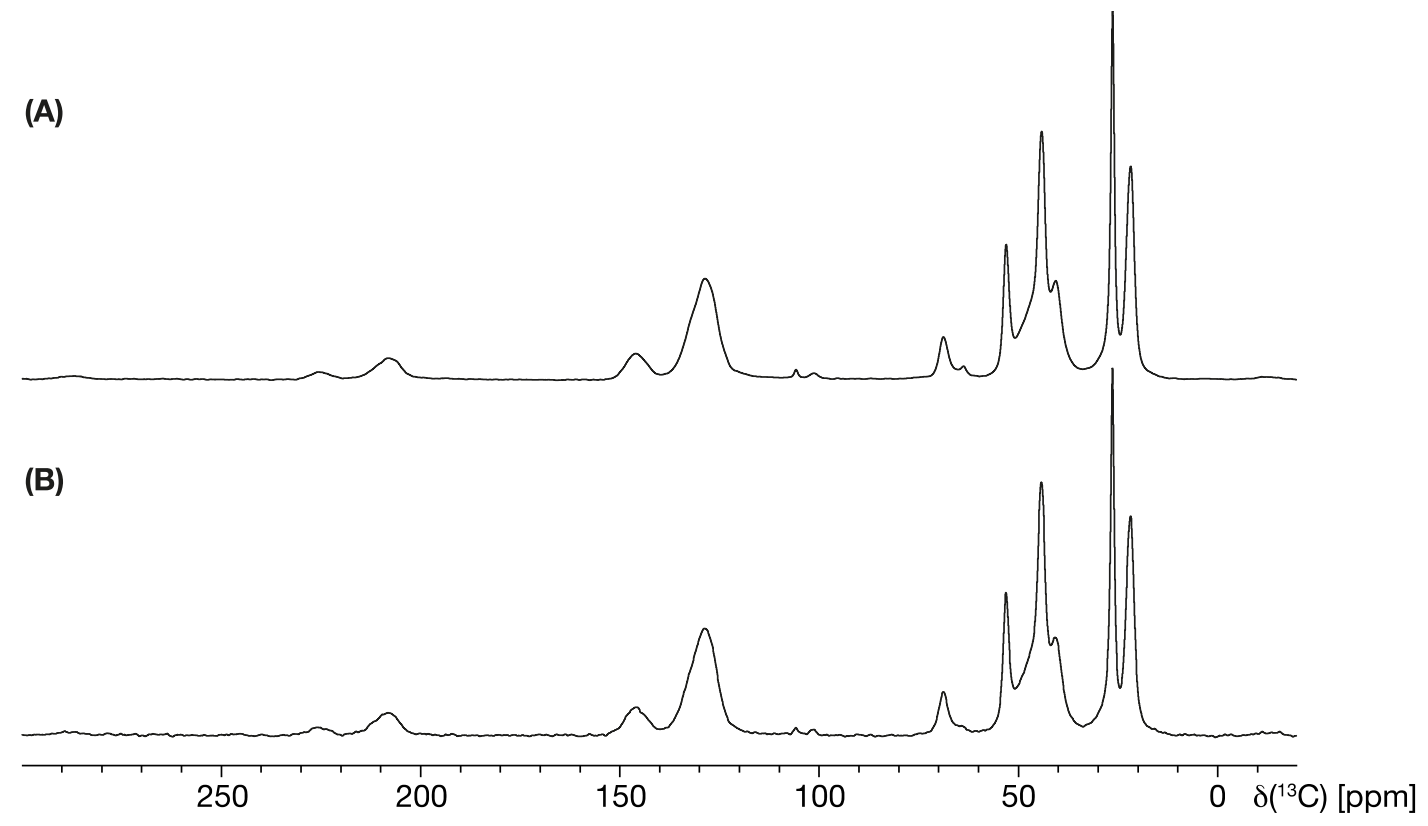

Figure 1. Conventional $\left\{{ }^{1} \mathrm{H}\right\}-{ }^{13} \mathrm{C}$ CPMAS spectra of $(\mathrm{A})$ unloaded and $(\mathrm{B}) 5.5 \mathrm{wt} \%$ selenate-loaded Smopex®103. The spectra were recorded at ambient temperature and a MAS rate of $12 \mathrm{kHz}$. Cross polarization was achieved by a ramped $\mathrm{rf}$ field on the ${ }^{1} \mathrm{H}$ channel rising from 90 to $100 \%$ of the maximum ${ }^{1} \mathrm{H}$ rf amplitude and lasting for a contact time of $1.50 \mathrm{~ms}$. The relaxation delay was $2.50 \mathrm{~s}$, the full spectral with was $789 \mathrm{ppm}$ and the acquisition time was 17.2 ms. During acquisition heteronuclear decoupling was applied at a ${ }^{1} \mathrm{H}$ rf 
amplitude of $83 \mathrm{kHz}$ using a ${ }^{1} \mathrm{H}$ SPINAL64 sequence. ${ }^{36} \mathrm{~A}$ total of 512 scans were coadded for the spectrum shown in (B), while 8192 scans were coadded for (A).

DNP-enhanced Solid-state ${ }^{13}$ C NMR

The substantial sensitivity gains that result from DNP are clear from ${ }^{13} \mathrm{C}$ NMR spectra of these Se remediation materials. Figure 2(A) shows a DNP-enhanced (microwaves on) $\left\{{ }^{1} \mathrm{H}\right\}-{ }^{13} \mathrm{C}$ CPMAS spectrum of $32 \mathrm{mg}$ of 5.5 ${ }_{w t} \%$ selenate-loaded Smopex ${ }^{\circledR}-103$ impregnated with $20 \mu \mathrm{L}$ of a $16 \mathrm{mM}$ solution of the radical AMUPol in glycerol- $\mathrm{d}_{8} / \mathrm{D}_{2} \mathrm{O} / \mathrm{H}_{2} \mathrm{O} 60: 30: 10 \mathrm{v} / \mathrm{v} / \mathrm{v}$. In the case of water remediation materials an aqueous DNP matrix is a more appropriate choice than one based on an organic solvent. Kobayashi et al. ${ }^{37}$ have shown that a matrix based on $100 \% \mathrm{D}_{2} \mathrm{O}$ should be considered for DNP-enhanced HETCOR measurements on hydrogen-rich species in order to prevent matrix signals from obscuring those arising from the sample, but we have not followed this approach here. The spectrum in (A) was recorded at a MAS rate of $8.8 \mathrm{kHz}$ and used a CP contact time of $500 \mu$ s. This is compared to an identical spectrum in (B) recorded with the microwaves turned off. A relatively short contact time was used to reduce the intensity of the glycerol resonances at approximately 65 and 73 ppm, arising from the DNP matrix. Apart from some small shifts in the line positions, the DNPenhanced spectrum and the conventional ${ }^{13} \mathrm{C}$ CPMAS spectrum shown in Figure 1(B) are similar, suggesting that neither the polymer fibres nor the grafted strong-base functionality are substantially modified by impregnation with the aqueous DNP matrix. To aid comparison the conventional 13C CPMAS spectrum of Figure 1(B) and DNP-enhanced spectrum of Figure 2(A) are plotted on the same Figure in the SI (Figure S1(A)

and (B)). The resulting DNP enhancement, measured from the relative integrated intensity of these two spectra, in Figure 2(A) and (B) is 28. For this sample preparation the DNP build-up time ( $T_{D N P}$ measured via $\left.{ }^{13} \mathrm{C} C \mathrm{CP}\right)$ was $4.9 \mathrm{~s}$ giving an optimal relaxation time of $6.9 \mathrm{~s}\left(1.4 \mathrm{~T}_{\mathrm{DNP}}\right)$. A DNP-enhanced ${ }^{13} \mathrm{C}$ spectrum with comparable signal-to-noise ratio (230:1) to that for the conventional spectrum (270:1) in Figure 1(B) can be acquired in just 16 scans (compared to 512) using a (less than optimal) $2.5 \mathrm{~s}$ relaxation delay which allows a better comparison between the two (see Figure S1(C) in the SI). The substantial reduction in experiment time is achieved despite the fact that the DNP-enhanced ${ }^{13} \mathrm{C}$ CPMAS spectrum was obtained with a smaller MAS rotor $(3.2 \mathrm{~mm})$ and a shorter contact time $(500 \mu \mathrm{s})$ compared with its the conventional counterpart (4 mm and $1.5 \mathrm{~ms})$, as well as a less than optimal relaxation delay. 


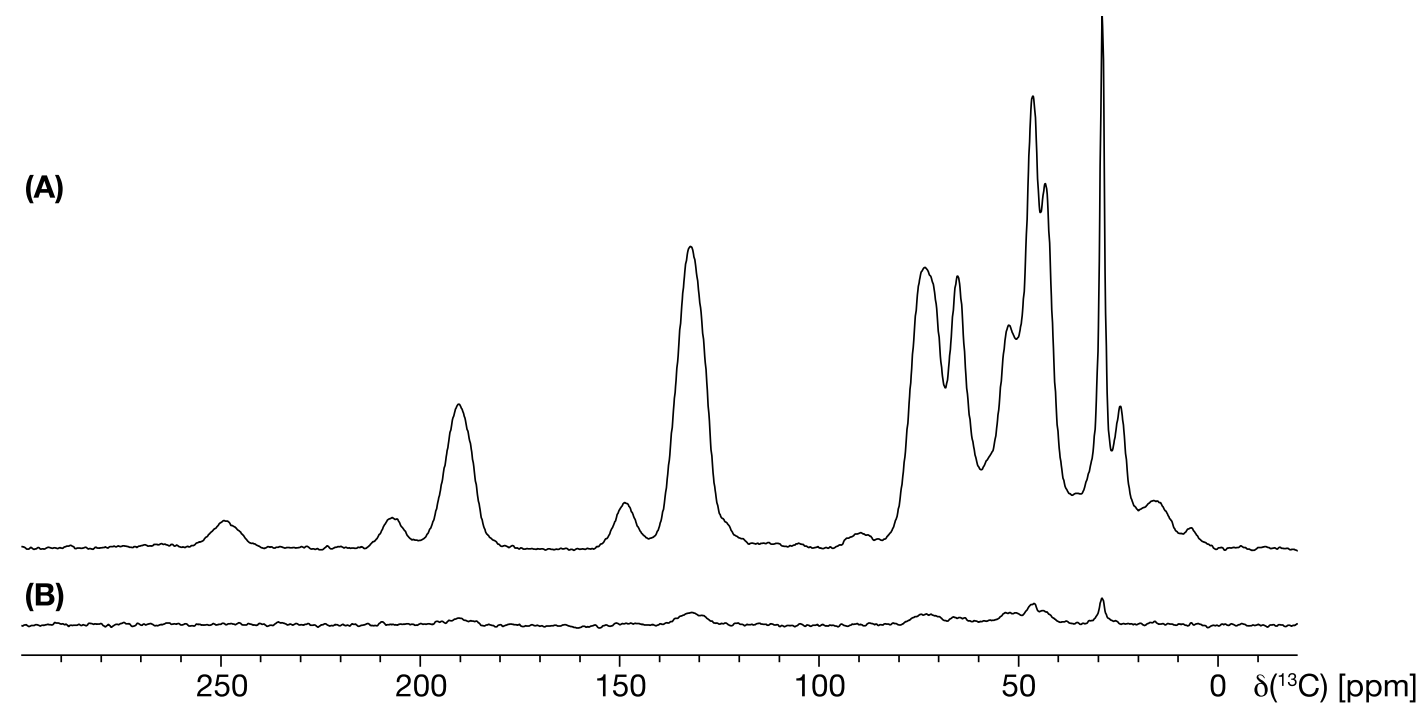

Figure 2(A). DNP-enhanced (microwave on) $\left\{{ }^{1} \mathrm{H}\right\}{ }^{-13} \mathrm{C}$ CPMAS spectrum of $5.5 \mathrm{wt} \%$ selenate-loaded Smopex ${ }^{\circledR}-$ 103 wetness. The spectrum was recorded at a MAS rate of $8.8 \mathrm{kHz}$. Cross polarization was achieved with a contact time of $500 \mu \mathrm{s}$. The relaxation delay was $5 \mathrm{~s}$, (less than the optimal value of $6.9 \mathrm{~s}$ ) the full spectral width was 502 ppm and the acquisition time was $13.5 \mathrm{~ms}$. During acquisition heteronuclear decoupling was applied at a ${ }^{1} \mathrm{H}$ rf amplitude of $86.2 \mathrm{kHz}$ using a ${ }^{1} \mathrm{H}$ swept-frequency TPPM sequence. ${ }^{38} \mathrm{~A}$ total of 8 scans were coadded. The ${ }^{13} \mathrm{C}$ chemical shift scale was referenced to TMS using glycerol as an internal secondary reference, fixing the low frequency resonance to $65.3 \mathrm{ppm}$. Other parameters are the same as for Figure 1. (B) $\left.\left\{{ }^{1} \mathrm{H}\right\}\right\}^{13} \mathrm{C} C \mathrm{CPMAS}$ spectrum of $5.5 \mathrm{wt} \%$ selenate-loaded Smopex ${ }^{\circledR}-103$ recorded as for (A) but with the microwaves turned off.

The reasonable DNP enhancement obtained makes the acquisition of DNP-enhanced two-dimensional $\left\{{ }^{1} \mathrm{H}\right\}-$ ${ }^{13} \mathrm{C}$ correlation spectra possible in a reasonable experiment time. Figure $3(\mathrm{~A})$ shows a DNP-enhanced $\left\{{ }^{1} \mathrm{H}\right\}-{ }^{13} \mathrm{C}$ PMLG $^{39}$ HETCOR spectrum of 5.5 wt $\%$ selenate-loaded Smopex ${ }^{\circledR}-103$ recorded with just 16 scans for each of $32 \mathrm{t}_{1}$ increments. The (less than optimal) relaxation delay of $2.85 \mathrm{~s}$ gave a total acquisition time of only $24 \mathrm{~min}$, but plenty of signal for analysis. This experiment used a short contact time of duration $50 \mu \mathrm{s}$, which completely removes the glycerol resonances arising from the DNP matrix. This allows a cross peak linking a proton resonance at around $5 \mathrm{ppm}$ with the methanaminium carbon peak at approximately $68 \mathrm{ppm}$ to be observed, but also causes a loss of signal for the quaternary aromatic peak at $146 \mathrm{ppm}$. In addition, there is a cross peak linking the aliphatic proton signal at about $2 \mathrm{ppm}$ to the $\mathrm{N}$-methyl carbons of the grafted $N, N, N$ trimethylmethanaminium cation at approximately 50 ppm. For longer contact times ( $>200 \mu \mathrm{s})$ a cross peak links the aromatic proton signal at about $7.1 \mathrm{ppm}$ to the glycerol ${ }^{13} \mathrm{C}$ resonances at approximately 65 and 73 ppm (see Figure S2 in the SI), indicating that the DNP solvent was well impregnated into the material. The quaternary aromatic peak is evident in the projection parallel to $v_{2}$ in this two-dimensional spectrum. 
${ }^{77} \mathrm{Se}$ NMR is challenging for these samples because of the low isotopic abundance $(7.63 \%)$ combined with the modest amount of selenate in the loaded remediation material (5.5 wt \%). To our knowledge only one example of DNP-enhanced ${ }^{77}$ Se solid-state NMR has been published previously, ${ }^{40}$ describing structural studies of CdSe quantum dots. Figure 3(B) shows a two-dimensional DNP-enhanced $\left\{{ }^{1} \mathrm{H}\right\}-{ }^{77}$ Se PMLG HETCOR spectrum of $5.5 \mathrm{wt} \%$ selenate-loaded Smopex ${ }^{\circledR}-103$ recorded at a MAS rate of $8.8 \mathrm{kHz}$ with a relatively long contact time of $2 \mathrm{~ms}$. This spectrum required 216 scans for each of $32 \mathrm{t}_{1}$ increments, and with the optimal relaxation delay of $6.9 \mathrm{~s}$ this gives a total experiment time of $13.2 \mathrm{hr}$. The experiment is only feasible because of the reasonable DNP enhancement obtained. Low sensitivity makes acquisition of a $\left\{{ }^{1} \mathrm{H}\right\}-{ }^{77} S e$ CPMAS spectrum without microwave irradiation for the purpose of measuring the ${ }^{77} \mathrm{Se}$ DNP enhancement too time consuming to be feasible. However, a conventional $\left\{{ }^{1} \mathrm{H}\right\}-^{77} \mathrm{Se}$ CPMAS spectrum can be obtained at ambient temperature, using a 7.5 mm MAS rotor filled with vacuum dried selenate-loaded Smopex®-103 (see Figure S3(A) in the SI). This spectrum is not fully comparable to the corresponding DNP-enhanced spectrum (Figure S3(B)), but the sensitivity per unit mass of the latter is approximately a factor of 9 greater than that of the former.

In the direct dimension the two-dimensional DNP-enhanced $\left\{{ }^{1} \mathrm{H}\right\}-{ }^{77}$ Se PMLG HETCOR spectrum shows a single ${ }^{77} \mathrm{Se}$ resonance at $1050 \mathrm{ppm}$ relative to $\left(\mathrm{CH}_{3}\right)_{2} \mathrm{Se}$ as expected for the $\mathrm{SeO}_{4}{ }^{2-}$ ion, indicating that no chemical modification takes place on absorption. However, despite the long contact time, this spectrum does not show the expected cross peak between the $\mathrm{SeO}_{4}{ }^{2-}$ resonance at $1050 \mathrm{ppm}$ and the methyl protons at 2 ppm, commensurate with location of the remediated anion close to the cation functionality. Instead, the single cross peak observed links the $\mathrm{SeO}_{4}{ }^{2-}$ resonance to a proton signal around $6 \mathrm{ppm}$. Note that both the methyl and methaminium protons are sufficiently immobilized at $100 \mathrm{~K}$ to cross polarize their directly bonded carbons, as shown in Figure 3(A), so that low cross polarization efficiencies associated with dynamics can be ruled out as a cause of the missing cross peak intensity. Another possibility is that at least some of the cross-peak intensity in the $\left\{{ }^{1} \mathrm{H}\right\}{ }^{-77} \mathrm{Se}$ spectrum results from a correlation between water molecules in the DNP matrix and the remediated $\mathrm{SeO}_{4}{ }^{2-}$ ions. However, cross polarization from protons in the remediation material to ${ }^{77} \mathrm{Se}$ in the $\mathrm{SeO}_{4}{ }^{2-}$ anions occurs even in the absence of any DNP matrix, as shown by the conventional $\left\{{ }^{1} \mathrm{H}\right\}{ }^{77} \mathrm{Se}$ CPMAS spectrum of a vacuum-dried sample (see Figure S3(A) in the SI). This observation suggests that contact between protons in the Smopex ${ }^{\circledR}-103$ and the $\mathrm{SeO}_{4}{ }^{2-}$ anions is responsible for at least a part of the cross-peak intensity in the DNP-enhanced $\left\{{ }^{1} \mathrm{H}\right\}{ }^{77}$ Se PMLG HETCOR spectrum. Given the lack of resolution in the indirect dimension of the $\left\{{ }^{1} \mathrm{H}\right\}-{ }^{13} \mathrm{C}$ HETCOR it is not possible to assign the proton chemical shift of the 
single cross peak in the $\left\{{ }^{1} \mathrm{H}\right\}-{ }^{77}$ Se HETCOR to a specific hydrogen environment. However, its chemical shift lies between that for the phenyl ring protons $(7.1 \mathrm{ppm})$ and the methaminium protons $(5 \mathrm{ppm})$ from the grafted 1 -(phenyl)- $N, N, N$-trimethylmethanaminium cation sidechains. This in turn implies that the remediated $\mathrm{SeO}_{4}{ }^{2-}$ ions are absorbed by the Smopex®-103 materials in a more complex fashion than via a simple ionic interaction with the cation responsible for the ion exchange. The proximity in space to the phenyl ring evidenced by the cross peak in the $\left\{{ }^{1} \mathrm{H}\right\}{ }^{77}$ Se PMLG HETCOR spectrum implies a specific supramolecular interaction which might help to explain the high selectivity of this remediation material for $\mathrm{SeO}_{4}{ }^{2-}$ in the presence of, for example, $\mathrm{SO}_{4}{ }^{2}$. Possibilities include anion- $\pi$ interactions with adjacent rings along the polymer chain, but this would normally involve a more electron deficient $\pi$-system, or weak $\mathrm{C}$-H hydrogen bonding interactions, which might explain the unusual proton chemical shift.

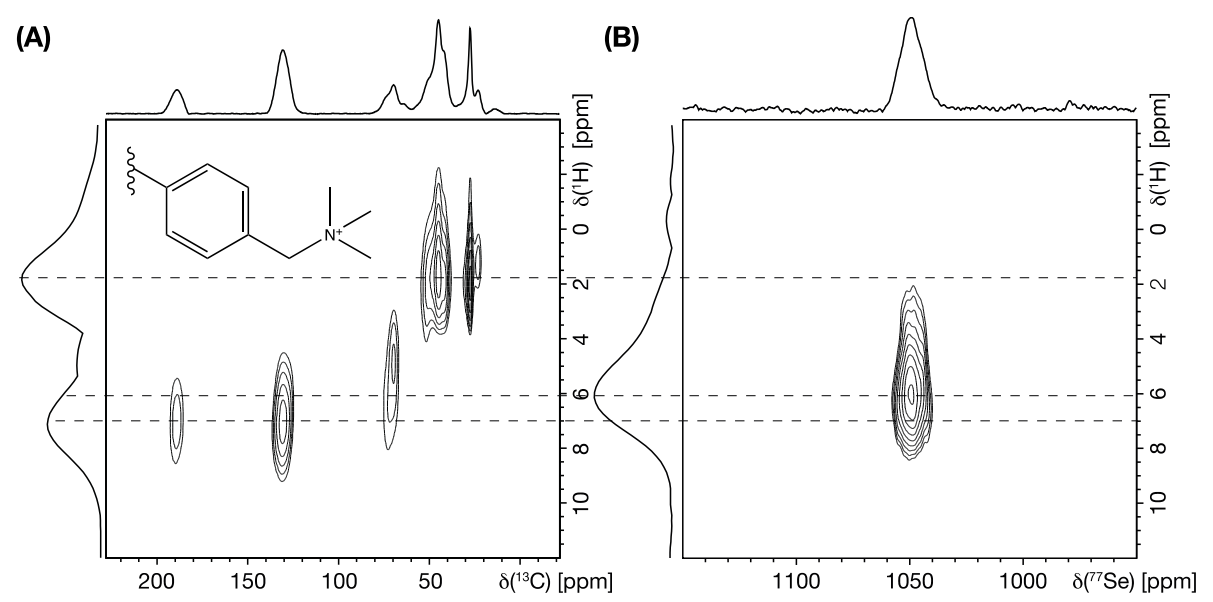

Figure 3(A). Expanded DNP-enhanced $\left\{{ }^{1} \mathrm{H}\right\}-{ }^{13} \mathrm{C}$ PMLG HETCOR spectrum of selenate-loaded Smopex®-103 recorded with a contact time of $50 \mu \mathrm{s}$, as described in the text. Sign discrimination was achieved in the indirect dimension by time proportional phase incrementation. The $t_{1}$ increment was $32.8 \mu \mathrm{s}$, giving a spectral width in the indirect dimension of $30.49 \mathrm{kHz}$. After taking the PMLG scaling factor of 0.47 (measured in a separate experiment) into account this gives a full spectral width of $23.8 \mathrm{ppm}$. Other parameters are as described in Figure 2. The inset shows the chemical structure of the functionalizing side chain to aid the assignment of the two-dimensional spectrum. (B) Expanded DNP-enhanced $\left\{{ }^{1} \mathrm{H}\right\}-$ 77Se PMLG HETCOR spectrum recorded with a contact time of $2 \mathrm{~ms}$, as described in the text. The $\mathrm{t}_{1}$ increment and other indirect dimension parameters were identical to those for Figure 3(A). 


\section{Conclusions}

This study of Se remediation materials manufactured from synthetic scavengers based on polymer fibres makes use of DNP-enhanced solid-state NMR $\left\{{ }^{1} \mathrm{H}\right\}-{ }^{77}$ Se correlation experiments to give information about the binding between the remediated $\mathrm{SeO}_{4}^{2-}$ ions with the grafted side chains which provide the required ion exchange functionality. These spectra suggest that $\mathrm{SeO}_{4}{ }^{2-}$ absorption involves a supramolecular interaction in addition to the ionic interaction with the functionalizing cation, which might help to explain the high selectivity of this remediation material for $\mathrm{SeO}_{4}{ }^{2-}$ in the presence of, for example, $\mathrm{SO}_{4}{ }^{2-}$. This study demonstrates that the significant signal enhancement obtained with DNP-enhanced solid-state NMR allows the efficient acquisition of $\left\{{ }^{1} \mathrm{H}\right\}{ }^{77}$ Se correlation experiments even for systems for which the Se is at relatively low concentration, and to our knowledge this is the first example of DNP-enhanced ${ }^{77}$ Se NMR beyond a straightforward one-dimensional MAS spectrum. The standard aqueous biradical solutions used for DNPenhanced solid-state NMR are an ideal way to obtain the required homogeneous distribution of polarizing agent throughout the polymer fibres of these water remediation materials.

\section{Acknowledgements}

The $600 \mathrm{MHz} / 395 \mathrm{GHz}$ DNP spectrometer used in this work was purchased with funding from EPSRC's Strategic Equipment Panel (EP/L022524) and the University of Nottingham, UK. MM thanks EPSRC and Johnson Matthey, UK for a PhD Studentship funded under the EPSRC industrial CASE scheme.

\section{References}

1 T. Maly, G. T. Debelouchina, V. S. Bajaj, K.-N. Hu, C.-G. Joo, M. L. Mak-Jurkauskas, J. R. Sirigiri, P. C. A. van der Wel, J. Herzfeld, R. J. Temkin and R. G. Griffin, J. Chem. Phys., 2008, 128, 052211.

2 M. Rosay, L. Tometich, S. Pawsey, R. Bader, R. Schauwecker, M. Blank, P. M. Borchard, S. R. Cauffman, K. L. Felch, R. T. Weber, R. J. Temkin, R. G. Griffin and W. E. Maas, Phys. Chem. Chem. Phys., 2010, 12, 5850-5860.

3 Q. Z. Ni, E. Daviso, T. V. Can, E. Markhasin, S. K. Jawla, T. M. Swager, R. J. Temkin, J. Herzfeld and R. G. Griffin, Acc. Chem. Res., 2013, 46, 1933-1941.

4 A. J. Rossini, A. Zagdoun, M. Lelli, A. Lesage, C. Copéret and L. Emsley, Acc. Chem. Res., 2013, 46, 1942-1951.

5 A. S. L. Thankamony, J. J. Wittmann, M. Kaushik and B. Corzilius, Prog. Nucl. Magn. Reson. Spectrosc., 2017, 102-103, 120-195.

6 K.-N. Hu, H.-H. Yu, T. M. Swager and R. G. Griffin, J. Am. Chem. Soc., 2004, 126, 10844-10845.

7 Y. Matsuki, T. Maly, O. Ouari, H. Karoui, F. Le Moigne, E. Rizzato, S. Lyubenova, J. Herzfeld, T. Prisner, P. Tordo and R. G. Griffin, Angew. Chem. Int. Ed. Engl., 2009, 48, 4996-5000.

8 A. Zagdoun, G. Casano, O. Ouari, M. Schwarzwälder, A. J. Rossini, F. Aussenac, M. Yulikov, G. Jeschke, C. Copéret, A. Lesage, P. Tordo and L. Emsley, J. Am. Chem. Soc., 2013, 135, 12790-12797.

9 C. Sauvée, M. Rosay, G. Casano, F. Aussenac, R. T. Weber, O. Ouari and P. Tordo, Angew. Chem. Int. Ed. Engl., 2013, 52, 10858-10861.

10 V. S. Bajaj, M. K. Hornstein, K. E. Kreischer, J. R. Sirigiri, P. P. Woskov, M. L. Mak-Jurkauskas, J. Herzfeld, R. J. Temkin and R. G. Griffin, J. Magn. Reson., 2007, 189, 251-279. 
11 E. Pump, A. Bendjeriou-Sedjerari, J. Viger-Gravel, D. Gajan, B. Scotto, M. K. Samantaray, E. AbouHamad, A. Gurinov, W. Almaksoud, Z. Cao, A. Lesage, L. Cavallo, L. Emsley and J.-M. Basset, Chem. Sci., 2018, 9, 4866-4872.

12 M. Mais, S. Paul, N. S. Barrow and J. J. Titman, Johnson Matthey Technol. Rev., 2018, 62, 271-278.

13 M. Leskes, G. Kim, T. Liu, A. L. Michan, F. Aussenac, P. Dorffer, S. Paul and C. P. Grey, J. Phys. Chem. Lett., 2017, 8, 1078-1085.

14 P. Berruyer, M. Lelli, M. P. Conley, D. L. Silverio, C. M. Widdifield, G. Siddiqi, D. Gajan, A. Lesage, C. Copéret and L. Emsley, J. Am. Chem. Soc., 2017, 139, 849-855.

15 F. A. Perras, J. D. Padmos, R. L. Johnson, L.-L. Wang, T. J. Schwartz, T. Kobayashi, J. H. Horton, J. A. Dumesic, B. H. Shanks, D. D. Johnson and M. Pruski, J. Am. Chem. Soc., 2017, 139, 2702-2709.

16 T. Kobayashi, F. A. Perras, I. I. Slowing, A. D. Sadow and M. Pruski, ACS Catal., 2015, 5, 7055-7062.

17 D. Lee, N. T. Duong, O. Lafon and G. De Paëpe, J. Phys. Chem. C, 2014, 118, 25065-25076.

18 A. S. Lilly Thankamony, C. Lion, F. Pourpoint, B. Singh, A. J. Perez Linde, D. Carnevale, G. Bodenhausen, H. Vezin, O. Lafon and V. Polshettiwar, Angew. Chem. Int. Ed. Engl., 2015, 54, 2190-2193. A. Lesage, M. Lelli, D. Gajan, M. A. Caporini, V. Vitzthum, P. Mieville, J. Alauzun, A. Roussey, C. Thieuleux, A. Mehdi, G. Bodenhausen, C. Copéret and L. Emsley, J. Am. Chem. Soc., 2010, 132, 1545915461.

20 A. S. L. Thankamony, O. Lafon, X. Lu, F. Aussenac, M. Rosay, J. Trebosc, H. Vezin and J.-P. Amoureux, Appl. Magn. Reson., 2012, 43, 237-250.

21 W. R. Gunther, V. K. Michaelis, M. A. Caporini, R. G. Griffin and Y. Román-Leshkov, J. Am. Chem. Soc., 2014, 136, 6219-6222.

22 F. Blanc, S. Y. Chong, T. O. McDonald, D. J. Adams, S. Pawsey, M. A. Caporini and A. I. Cooper, J. Am. Chem. Soc., 2013, 135, 15290-15293.

23 O. Lafon, A. S. L. Thankamony, T. Kobayashi, D. Carnevale, V. Vitzthum, I. I. Slowing, K. Kandel, H. Vezin, J.-P. Amoureux, G. Bodenhausen and M. Pruski, J. Phys. Chem. C, 2013, 117, 1375-1382.

24 F. Ziarelli, M. Casciola, M. Pica, A. Donnadio, F. Aussenac, C. Sauvée, D. Capitani and S. Viel, Chem. Commun., 2014, 50, 10137-10139.

25 Ü. Akbey, B. Altin, A. Linden, S. Özçelik, M. Gradzielski and H. Oschkinat, Phys. Chem. Chem. Phys., 2013, 15, 20706.

26 A. C. Pinon, J. Schlagnitweit, P. Berruyer, A. J. Rossini, M. Lelli, E. Socie, M. Tang, T. Pham, A. Lesage, S. Schantz and L. Emsley, J. Phys. Chem. C, 2017, 121, 15993-16005.

27 S. R. Taylor, Geochimica et Cosmochimica Acta, 1964, 28, 1273-1285.

28 J. Alexander, in Handbook on the Toxicology of Metals, Academic Press, San Diego, 2015, pp. 1175-1208.

29 Guidelines for Drinking Water Quality, World Health Organization, $4^{\text {th }}$ edition, 2017.

30 European Council Directive 98/83/EC of 3 November 1998. Off. J. Eur. Union 1998, 330:32-54.

31 S. Santos, G. Ungureanu, R. Boaventura and C. Botelho, Science of The Total Environment, 2015, 521-522, 246-260.

32 L. C. Tan, Y. V. Nancharaiah, E. D. van Hullebusch and P. N. L. Lens, Biotechnology Advances, 2016, 34, 886-907.

33 H. Ullah, G. Liu, B. Yousaf, M. U. Ali, S. Irshad, Q. Abbas and R. Ahmad, Environmental Geochemistry and Health, 2018, 1-33.

34 Y. He, Y. Xiang, Y. Zhou, Y. Yang, J. Zhang, H. Huang, C. Shang, L. Luo, J. Gao and L. Tang, Environmental Research, 2018, 164, 288-301.

35 C. MacNamara, J. Torroba and A. Deacon, Johnson Matthey Technol. Rev., 2015, 59, 334-352.

36 B. M. Fung, A. K. Khitrin and K. Ermolaev, J. Magn. Reson., 2000, 142, 97-101.

37 T. Kobayashi, F. A. Perras, U. Chaudhary, I. I. Slowing, W. Huang, A. D. Sadow and M. Pruski, Solid State Nucl. Magn. Reson., 2017, 87, 38-44.

38 R. S. Thakur, N. D. Kurur and P. K. Madhu, Chem. Phys. Lett., 2006, 426, 459-463.

39 E. Vinogradov, P. K. Madhu and S. Vega, Chem. Phys. Lett., 1999, 314, 443-450.

40 L. Piveteau, T.-C. Ong, A. J. Rossini, L. Emsley, C. Copéret and M. V. Kovalenko, J. Am. Chem. Soc., 2015, 137, 13964-13971. 